\title{
Cylindrical Dielectric Resonator Antenna Offering Low Cross-Polarization for Point-to-Point Communication Systems
}

\author{
P Soni REDDY, Rahul MONDAL, Partha Pratim SARKAR \\ Department of Engineering \& Technological Studies, University of Kalyani, West Bengal - 741235, India \\ p.sonireddy@gmail.com, rahul.mondal740@gmail.com,parthabe91@yahoo.co.in \\ Submitted April 11, 2020 / Accepted February 14, 2021
}

\begin{abstract}
In this paper, a cylindrical dielectric resonator antenna (CDRA) offering low cross-polarization (XP) for point-to-point communication systems is presented. Three linear arrays of air vias ( $L A A V)$ are incorporated along the $H$-plane of a conventional CDRA in order to weaken the undesired XP generating fields due to the orthogonally resonating $H E M_{21 \delta}$ mode. A set of parametric studies are conducted on the design parameters of the 3-LAAV in CDRA to understand the sensitivity of boresight XPD on the 3-LAAV design parameters. Field distributions in CDRA before and after the incorporation of $L A A V$ are extensively studied to draw a conclusive inference. The 3-LAAV loaded CDRA offers $39 \mathrm{~dB}$ higher boresight XP suppression in comparison to the conventional CDRA. The proposed technique is experimentally validated. The measured result shows an XP isolation of $56 \mathrm{~dB}$ at the boresight, $55 \mathrm{~dB}$ and $38 \mathrm{~dB}$ over $\pm 15 \%$ of half-power beamwidth (HPBW) in the E-plane and H-plane of radiation, respectively. This result is well above the minimum cross-polarization discrimination $(X P D)$ requirements for the satellite earth station antennas.
\end{abstract}

\section{Keywords}

Cross-polarization, dielectric resonator antenna, pointto-point communication, parabolic reflector antenna

\section{Introduction}

Electromagnetic radiation in undesired polarization states is often referred to as cross-polarized (XP) radiation [1]. The co-existence of high undesired XP components with the desired polarization components leads to severe degradation in the overall system performance in point-topoint applications. Poor spatial resolution due to reduced beam efficiency of antenna systems for microwave radiometers [2], [3], and increased cross-talk between the adjacent channels in a communication link [4], [5] are few instances of the undesired effects of high XP in practical applications that have been in the focus of antenna engineers during the last few decades. Over the years, dielectric resonator antenna (DRA) has evolved as a more efficient alternative to microstrip antenna for point-to-point applications offering high radiation efficiency, and high power handling capability [6].

High boresight cross-polarization discrimination (XPD) is an essential requirement for satellite ground station [7] and fixed radio antenna applications [8]. As per European Telecommunications Standards Institute (ETSI), the general XPD requirement for such applications is at least $30 \mathrm{~dB}$ at antenna boresight and over $\pm 15 \%$ of the halfpower beamwidth (HPBW). Stable radiation characteristics with XPD greater than $40 \mathrm{~dB}$ at the antenna boresight and $25 \mathrm{~dB}$ across its HPBW are essential for high precision tracking [9]. In this regard, cylindrical DRA (CDRA) resonating in $\mathrm{HEM}_{11 \delta}$ mode has been explored in majority by the antenna researchers [10-14].

Kajfez et al. in their work [10] presented the field distribution of different resonant modes in CDRA which acts as the basic guideline for identifying the non-radiating modes $\left(\mathrm{HEM}_{21 \delta}\right)$, their polarization states, and frequency spacing between the modes. Al-Zoubi et al. [11] proposed a novel technique of wrapping metal strips on DRA for achieving peak XP suppression of $20 \mathrm{~dB}$. Differential feeding mechanism, presented by Singh and Sharma [12], is another method for obtaining low peak XP levels of around $-40 \mathrm{~dB}$ to $-20 \mathrm{~dB}$. Guha et al. in their research works [13], [14] presented significant findings in terms of identification of XP generating factor $\left(\mathrm{HEM}_{21 \delta}\right.$ mode), experimental validation, and subsequently its mitigation using metallic [13] and dielectric [14] perturbation techniques. Around $8 \mathrm{~dB}$ to $10 \mathrm{~dB}$ peak XP suppression is achieved by employing these techniques. The metallic perturbation techniques discussed in [11] and [13] suppresses the XP radiations due to inductive loading effect. However, the use of metallic perturbations in CDRA increases ohmic loss as a result the overall antenna radiation efficiency may get affected.

The present article documents a low XP probe-fed CDRA resonating in $\mathrm{HEM}_{11 \delta}$ mode for point-to-point applications. 


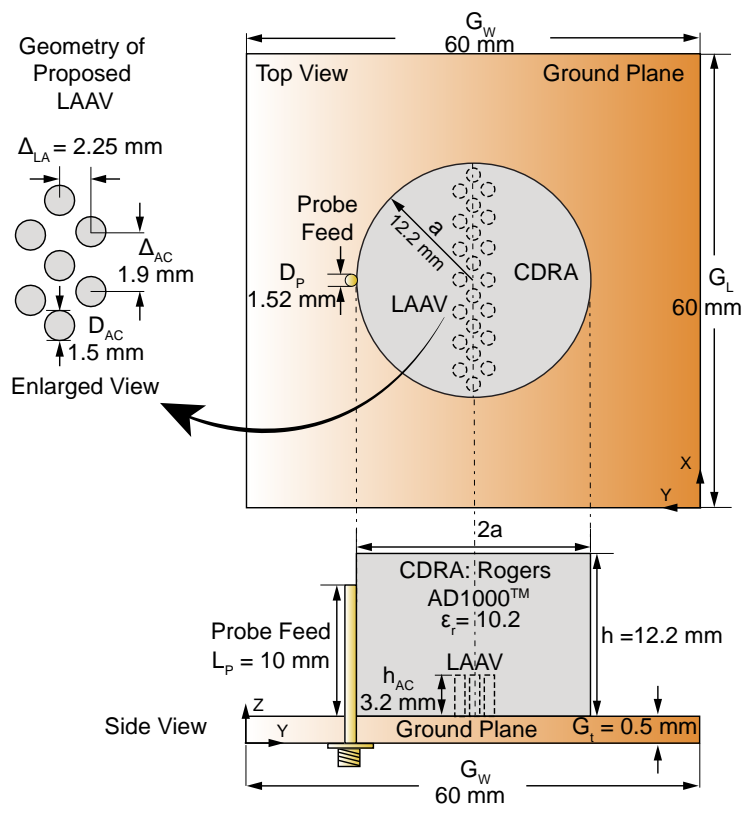

Fig. 1. Detailed geometry of the proposed 3-LAAV loaded CDRA for $\mathrm{HEM}_{11 \delta}$ mode resonating at $3.25 \mathrm{GHz}$ with optimized dimension values.

A novel three linear arrays of air vias (3-LAAV) structure has been presented as an effective permittivity modifier in CDRA for XP suppression. Air vias in CDRA has been used in literature for enhancing antenna bandwidth [15-17]. But, the possibility of suppressing XP radiations in probefed CDRA using air vias through capacitive loading effect is explored for the first time in this paper. The XP generating factors have been studied with the prime focus on identifying the region(s) where the XP fields are confined. Thereafter, a thorough analysis on mitigating the $\mathrm{XP}$ radiations using the proposed 3-LAAV has been conducted by studying the effect of air vias on the fields inside and below the CDRA. Detailed investigations on the dimensions and location of the air vias in CDRA have been conducted for achieving optimum XP suppression. Ansys ${ }^{\circledR} \mathrm{HFSS}^{T M}$ software simulator was used to design and simulate all antenna structures.

\section{Antenna Geometry and Design Con- cept}

The detailed geometry of the proposed 3-LAAV loaded CDRA resonating in $\mathrm{HEM}_{11 \delta}$ mode at $3.25 \mathrm{GHz}$ is shown in Fig. 1. A cylindrical dielectric slab of radius $a=12.2 \mathrm{~mm}$ and height $h=12.2 \mathrm{~mm}$ is designed using Rogers $\mathrm{AD} 1000^{T M} \mathrm{di}-$ electric material with relative permittivity $\left(\epsilon_{\mathrm{r}}\right)=10.2$ and loss tangent $(\tan \delta)=0.0023$. This cylindrical dielectric slab is placed on a metallic ground plane of dimension $0.65 \lambda_{0} \times 0.65 \lambda_{0}$, where $\lambda_{0}$ is the free-space wavelength corresponding to the resonating frequency of the conventional CDRA. The CDRA is fed using coaxial probe of length $L_{\mathrm{P}}=$ $9 \mathrm{~mm}$ and diameter $D_{\mathrm{P}}=1.52 \mathrm{~mm}$. Three linear arrays of air vias (3-LAAV) each of diameter $D_{\mathrm{AC}}=1.5 \mathrm{~mm}$ and height $h_{\mathrm{AC}}=3.2 \mathrm{~mm}$ are grooved into the dielectric slab. The spacing between each air cavity in a linear array is $\Delta_{A C}=1.9 \mathrm{~mm}$.

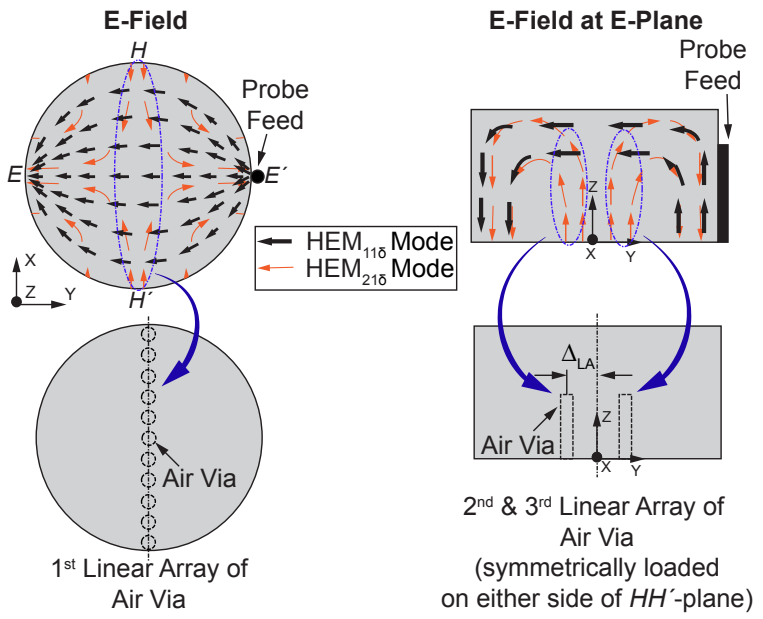

(b)

Fig. 2. Design methodology of the proposed 3-LAAV loaded CDRA along with the E-field distribution of the desired $\mathrm{HEM}_{11 \delta}$ mode and higher order $\mathrm{HEM}_{21 \delta}$ mode. (a) Top View (b) Side View. $E E^{\prime}$ and $H H^{\prime}$ indicates the E-pane and H-plane of the antenna.

The gap between each linear array is $\Delta_{L A}=2.25 \mathrm{~mm}$.

The detailed design methodology of the proposed 3LAAV loaded CDRA is shown in Fig. 2. The excitation of the undesired orthogonally resonating non-radiating mode $\left(\mathrm{HEM}_{21 \delta}\right)$ along with the desired mode $\left(\mathrm{HEM}_{11 \delta}\right)$ generates high XP levels in conventional CDRA. Ideally, as depicted in Fig. 2(a), the E-field distribution of $\mathrm{HEM}_{21} \delta$ mode is symmetric across the H-plane. But practically, as depicted in Fig. 2(b), due to the asymmetry caused by the probe across the H-plane of the CDRA, the fields may appear to be slightly disproportionate across the H-plane. This inference guides in the strategic placement of the $1^{s t}$ linear array of air vias spanning across the center and the other two linear arrays of air vias $\left(2^{\text {nd }}\right.$ and $\left.3^{\text {rd }}\right)$ symmetrically across a marginal space $\left(\Delta_{\mathrm{LA}}\right)$ on either side of the H-plane. The concept of incorporating air vias into the dielectric material is introduced here as a technique for dissipating the weak fields due to the undesired $\mathrm{HEM}_{21 \delta}$ mode by effectively decreasing the permittivity of dielectric material along the H-plane. The desired $\mathrm{HEM}_{11 \delta}$ mode however remains unaffected by the loading of the proposed 3-LAAV into the CDRA.

\section{LAAV: Simulated Results and Phys- ical Analysis}

The $S_{11}$ and radiation characteristics of the CDRA with and without LAAV in both the principal radiation planes are given in Fig. 3. Due to the loading of LAAV (three LAAV and single LAAV) in CDRA a considerable suppression of the undesired $\mathrm{HEM}_{21 \delta}$ mode is observed from the $S_{11}$ characteristics given in Fig. 3(a). Greater suppression of $\mathrm{HEM}_{21 \delta}$ mode is achieved using 3-LAAV compared to single array of LAAV (1-LAAV). No significant deviation in the resonant frequency of the desired $\mathrm{HEM}_{11 \delta}$ mode is observed due to the incorporation of LAAV into the conventional CDRA. 


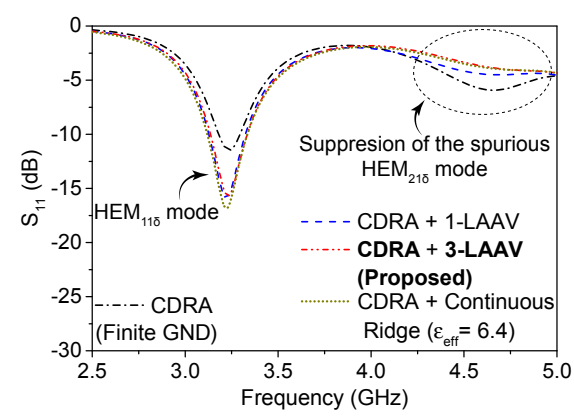

(a)

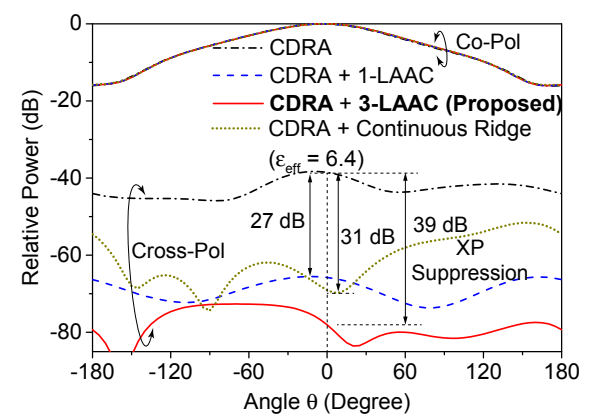

(b)

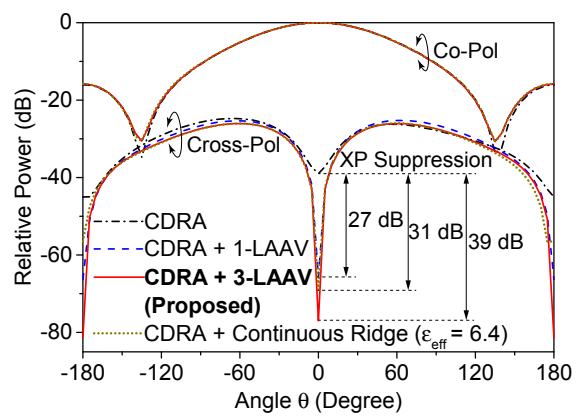

(c)

Fig. 3. Simulated (a) $S_{11}$ vs. frequency characteristics, (b) Normalized radiation patterns in E-plane, (c) Normalized radiation patterns in H-plane for the conventional CDRA (with finite ground plane), proposed LAAV loaded CDRA and continuous dielectric ridge loaded CDRA.

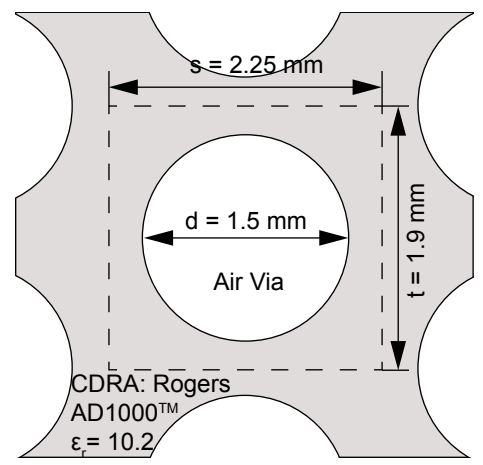

Fig. 4. Geometry of the unit cell of the proposed 3-LAAV structure incorporated into the CDRA. The dashed box represents the unit cell.

A simultaneous study has been conducted by exchanging the 3-LAAV structure with a continuous dielectric ridge having an effective permittivity given by the density of the air cavities present along the H-plane [18]. The geometry of the unit cell of the proposed 3-LAAV structure incorporated inside the CDRA is given in Fig. 4. The effective permittivity of the ridge is approximated by 1 :

$$
\epsilon_{\mathrm{eff}}=\epsilon_{\mathrm{r}}\left[1-\left(\frac{\pi}{4}\left(\frac{d^{2}}{s t}\right)\right)\right]+\left(\frac{\pi}{4}\left(\frac{d^{2}}{s t}\right)\right),
$$

where $\epsilon_{\mathrm{r}}=10.2$ is the relative permittivity of the solid cylindrical dielectric block of the CDRA, $d$ is the diameter of the air via, $s$ is the length and $t$ is the width of the unit cell box. The effective relative permittivity of the ridge is found to be equal to 6.4. In Fig. 3(a), the nature of higher order mode suppression achieved by the continuous dielectric ridge is found to be similar to the suppression offered by the proposed 3-LAAV structure. The 3-LAAV structure acts as an effective permittivity modifier of the region where the XP generating higher order mode is present from 10.2 to 6.4. As a result, the spurious $\mathrm{HEM}_{21 \delta}$ mode resonance is shifted to higher frequencies and the coupling from the feeding probe to this spurious mode is effectively reduced. Thus, the isolation between the desired $\mathrm{HEM}_{11 \delta}$ mode and the spurious $\mathrm{HEM}_{21 \delta}$ mode is increased.

Compared to the conventional CDRA, 1-LAAV, 3LAAV and continuous ridge offer a boresight XP suppression of $27 \mathrm{~dB}, 39 \mathrm{~dB}$ and $31 \mathrm{~dB}$, respectively in both the principal radiation planes. An increment in the number of air vias from 1-LAAV to 3-LAAV makes the overall XP reduction performance superior by $12 \mathrm{~dB}$. The XP suppression offered by continuous dielectric ridge is comparable to that offered by the proposed 3-LAAV structure. The XP level for 3-LAAV loaded CDRA lies well below $-70 \mathrm{~dB}$ in the E-plane for all values of $\theta$. Whereas in the H-plane, the XP level for 3-LAAV loaded CDRA lie below $-26 \mathrm{~dB}$ for all values of $\theta$ with $-77 \mathrm{~dB}$ at the boresight and $-27 \mathrm{~dB}$ over the HPBW $\left( \pm 40^{\circ}\right)$. In addition to this, the effects of ground plane size on antenna XP levels have been analyzed using an infinite ground plane and it is found that the edges of the ground plane do not significantly contribute to the XP levels.

The performance of 3-LAAV structure in weakening the $\mathrm{HEM}_{21 \delta}$ mode can be understood by studying the vector E-fields corresponding to $\mathrm{HEM}_{21 \delta}$ mode for 3-LAAV structure as shown in Fig. 5. Due to the presence of the air vias near the H-plane of the CDRA the effective permittivity of the region is reduced from 10.2 to 6.4. As a result, the E-field vectors corresponding to the spurious mode get significantly scattered near the air vias in both the radiation planes as shown in Fig. 5(a) and Fig. 5(b). The E-field vectors corresponding to $\mathrm{HEM}_{21 \delta}$ mode at the top of the air via given in the inset indicate significant scattering along the circumference of the air via. The clustering of the E-field vectors near each air via causes the horizontal components of all scattered E-field vectors which are radially inward to vanish due to their mutual interaction in opposite phases. However, their weak vertical counterparts, having same phase, add in the far-field region resulting in weak radiation in $\mathrm{HEM}_{21 \delta}$ mode. Further, rounding of the edges of the air vias has also been studied in this regard and it is found that the scattering of the E-field vectors corresponding to the spurious mode along the circumference of the air via is more prominent in the sharp edge air vias compared to rounded edge air vias. The XP performance of LAAV can also be understood by studying the E-field distribution below the CDRA, i.e. on the ground plane. The E-field $\left(E_{z}\right)$ distribution for the desired $\mathrm{HEM}_{11 \delta}$ mode is plotted in Fig. 6 with respect to distance along the H-plane. 


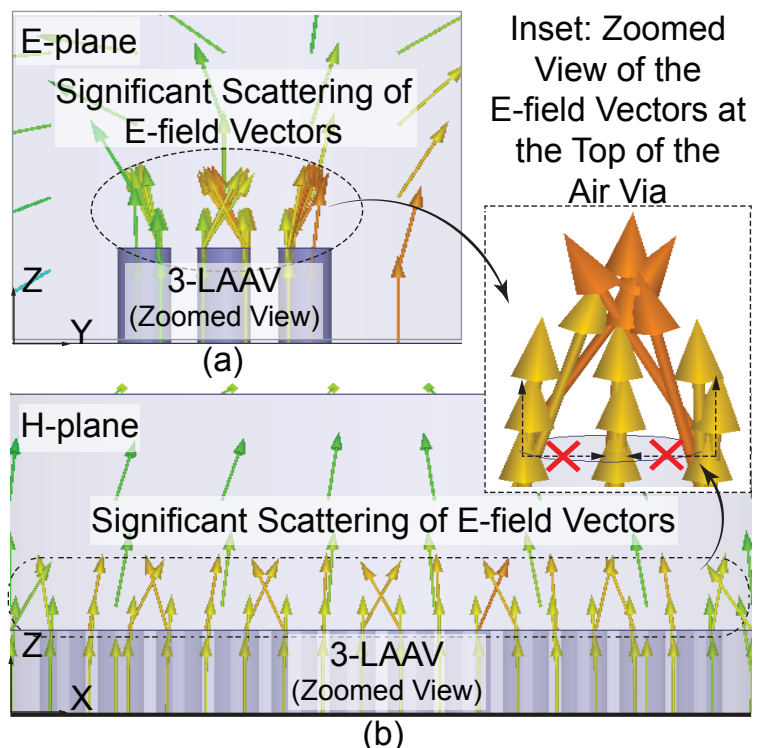

Fig. 5. Simulated E-field distribution of $\mathrm{HEM}_{21 \delta}$ mode at (a) E-plane and (b) H-plane of 3-LAAV loaded CDRA, respectively. Red and blue in the figures indicate maximum and minimum E-field magnitude values. Thick black line at the bottom in (b) indicates the ground plane. Inset figure: E-field vectors at the top of the circular air cavity of 3-LAAV structure.

Ideally, the E-field distribution for $\mathrm{HEM}_{11 \delta}$ mode should possess symmetric maxima on either side of the $\mathrm{H}$ plane with a distinct minima along the H-plane. However, due to the asymmetry introduced by the feed a distinct minima in the E-field distribution is not observed in the conventional CDRA as shown in Fig. 6(a). This deviation from the ideal E-field distribution in conventional CDRA can be estimated from the average E-field strength along the H-plane. The ideal E-field strength along the $\mathrm{H}$-plane for $\mathrm{HEM}_{11 \delta}$ mode in conventional CDRA is represented by the minimum value considered in the plot, i. e. $0 \mathrm{~V} / \mathrm{m}$. In Fig. 6 , the average E-field strength for conventional CDRA over the H-plane is found to be $129 \mathrm{~V} / \mathrm{m}$. The loading of 1-LAAV and 3-LAAV structures into the conventional CDRA displays average Efield strengths of $48 \mathrm{~V} / \mathrm{m}$ and $23 \mathrm{~V} / \mathrm{m}$, respectively.

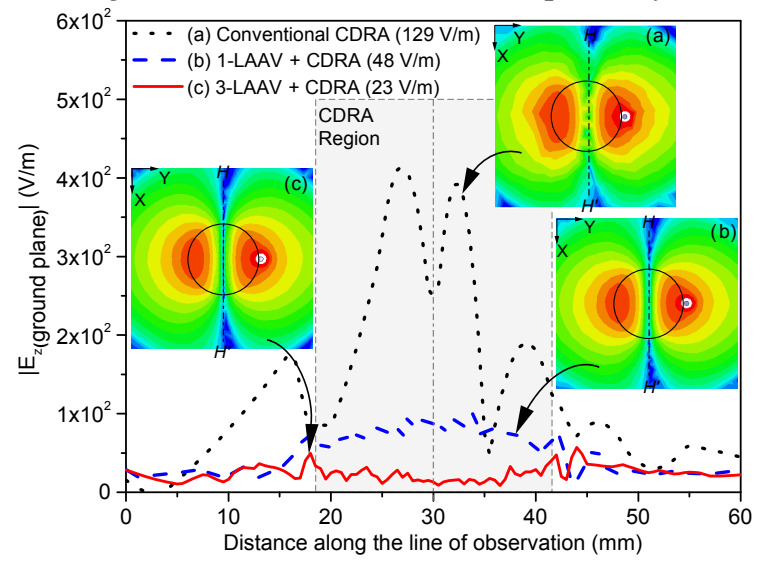

Fig. 6. Variation of ground plane E-field $\left(E_{\mathrm{Z}}\right)$ magnitude along the H-plane. Average E-field strength is displayed in the legend. Red and blue in the in-set figures $(\mathrm{a}-\mathrm{c})$ indicate maximum $(600 \mathrm{~V} / \mathrm{m})$ and minimum $(0 \mathrm{~V} / \mathrm{m})$ E-field magnitude values, respectively.
Clearly, the 3-LAAV structures show considerably better performance than 1-LAAV structures with maximum reduction in average E-field strengths of $106 \mathrm{~V} / \mathrm{m}$ in comparison to the conventional CDRA. Incorporating 3-LAAV into the conventional CDRA reinforces the near-ideal E-field distribution of the desired $\mathrm{HEM}_{11 \delta}$ mode. A distinct minima along the H-plane is observed using 3-LAAV compared to the other structures as shown in Fig. 6 in the inset figures (a)-(c).

\section{Parametric Analysis of the Proposed 3-LAAV Structure}

The sensitivity of the proposed antenna boresight XP level with the variation of 3-LAAV parameters $\left(D_{\mathrm{AC}}, h_{\mathrm{AC}}\right.$, $\left.\Delta_{\mathrm{AC}}, \Delta_{\mathrm{LA}}\right)$ and probe height $\left(L_{\mathrm{P}}\right)$ is studied in this section. In this study only one parameter is varied at a time while all other parameters are kept constant. The diameter $D_{\text {AC }}$ of each air cavity constituting the 3 -LAAV is varied from $1.1 \mathrm{~mm}$ to $1.9 \mathrm{~mm}$ with $0.2 \mathrm{~mm}$ step size keeping $h_{\mathrm{AC}}$, $\Delta_{\mathrm{AC}}, \Delta_{\mathrm{LA}}$ and $L_{\mathrm{P}}$ constant at $3.2 \mathrm{~mm}, 1.9 \mathrm{~mm}, 2.25 \mathrm{~mm}$ and $10 \mathrm{~mm}$, respectively. Maximum isolation between the desired $\mathrm{HEM}_{11 \delta}$ mode and the spurious $\mathrm{HEM}_{21 \delta}$ mode is obtained at $D_{\mathrm{AC}}=1.5 \mathrm{~mm}$. The height $h_{\mathrm{AC}}$ of each air cavity in 3-LAAV is varied from $2.8 \mathrm{~mm}$ to $3.6 \mathrm{~mm}$ with a step size of $0.2 \mathrm{~mm}$ keeping $D_{\mathrm{AC}}, \Delta_{\mathrm{AC}}, \Delta_{\mathrm{LA}}$ and $L_{\mathrm{P}}$ constant at $1.5 \mathrm{~mm}, 1.9 \mathrm{~mm}, 2.25 \mathrm{~mm}$ and $10 \mathrm{~mm}$, respectively. Maximum isolation between the desired $\mathrm{HEM}_{11 \delta}$ mode and the spurious $\mathrm{HEM}_{21 \delta}$ mode is obtained at $h_{\mathrm{AC}}=3.2 \mathrm{~mm}$. The spacing $\Delta_{\mathrm{AC}}$ between each air cavity in a linear array is varied from $1.7 \mathrm{~mm}$ to $2.1 \mathrm{~mm}$ with a step size of $0.1 \mathrm{~mm}$ keeping $D_{\mathrm{AC}}, h_{\mathrm{AC}}, \Delta_{\mathrm{LA}}$ and $L_{\mathrm{P}}$ constant at $1.5 \mathrm{~mm}, 3.2 \mathrm{~mm}, 2.25 \mathrm{~mm}$ and $10 \mathrm{~mm}$, respectively. Maximum isolation between the desired $\mathrm{HEM}_{11 \delta}$ mode and the spurious $\mathrm{HEM}_{21 \delta}$ mode is obtained at $\Delta_{\mathrm{AC}}=1.9 \mathrm{~mm}$. The gap $\Delta_{\mathrm{LA}}$ between the linear arrays is varied from $1.75 \mathrm{~mm}$ to $2.75 \mathrm{~mm}$ with a step size of $0.25 \mathrm{~mm}$ keeping $D_{\mathrm{AC}}, h_{\mathrm{AC}}, \Delta_{\mathrm{AC}}$ and $L_{\mathrm{P}}$ constant at $1.5 \mathrm{~mm}$, $3.2 \mathrm{~mm}, 1.9 \mathrm{~mm}$ and $10 \mathrm{~mm}$, respectively. Maximum isolation between the desired $\mathrm{HEM}_{11 \delta}$ mode and the spurious $\mathrm{HEM}_{21 \delta}$ mode is obtained at $\Delta_{\mathrm{LA}}=2.25 \mathrm{~mm}$. The height of the feeding probe $L_{\mathrm{P}}$ is varied from $9 \mathrm{~mm}$ to $12 \mathrm{~mm}$ with a step size of $1 \mathrm{~mm}$ keeping $D_{\mathrm{AC}}, h_{\mathrm{AC}}, \Delta_{\mathrm{AC}}$ and $\Delta_{\mathrm{LA}}$ constant at $1.5 \mathrm{~mm}, 3.2 \mathrm{~mm}, 1.9 \mathrm{~mm}$ and $2.25 \mathrm{~mm}$, respectively. Maximum isolation between the desired $\mathrm{HEM}_{11 \delta}$ mode and the spurious $\mathrm{HEM}_{21 \delta}$ mode is obtained at $L_{\mathrm{P}}=10 \mathrm{~mm}$. The variations in XP level at boresight for each of the parametric variations are illustrated in Fig. 7. The optimum values for $D_{\mathrm{AC}}, h_{\mathrm{AC}}, \Delta_{\mathrm{AC}}, \Delta_{\mathrm{LA}}$, and $L_{\mathrm{P}}$ for which maximum XP suppression is achieved are $1.5 \mathrm{~mm}, 3.2 \mathrm{~mm}, 1.9 \mathrm{~mm}, 2.25 \mathrm{~mm}$, and $10 \mathrm{~mm}$ respectively. The boresight XP values are found to be highly sensitive to minor variation of 3-LAAV design parameters. 


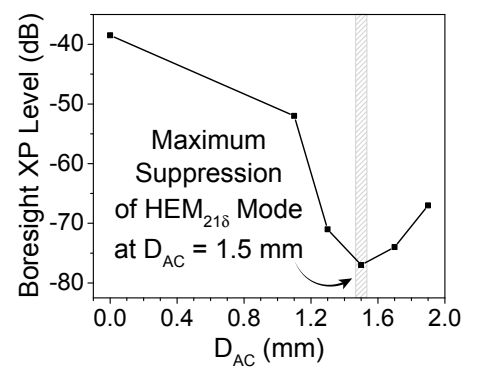

(a)

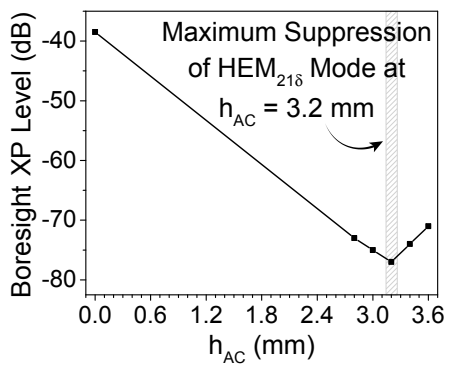

(b)

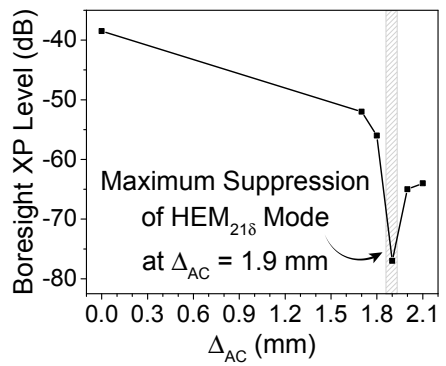

(c)

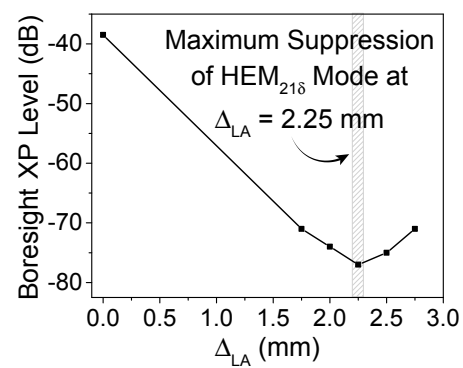

(d)

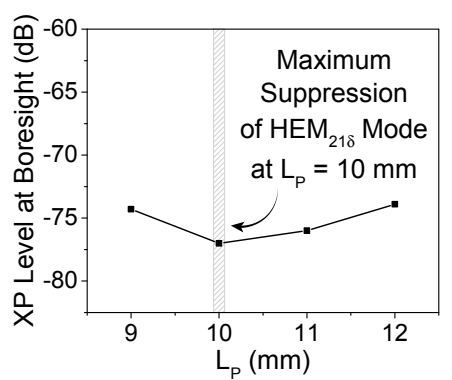

(e)

Fig. 7. Simulated (a) Boresight XP level vs. $D_{\mathrm{AC}}$ variation, (b) Boresight XP level vs. $h_{\mathrm{AC}}$ variation, (c) Boresight XP level vs. $\Delta_{\mathrm{AC}}$ variation, (d) Boresight XP level vs. $\Delta_{\mathrm{LA}}$ variation, and (e) Boresight XP level vs. $L_{\mathrm{P}}$ variation of the proposed 3-LAAV loaded CDRA at the desired $\mathrm{HEM}_{11 \delta}$ mode resonant frequency.

\section{Results and Discussion}

\subsection{Measured Results}

The proposed 3-LAAV loaded CDRA is fabricated for the experimental validation of the prototype. The snapshot of the fabricated prototype is given in Fig. 8. The $S_{11}$ characteristics of the proposed antenna is measured using a Rohde \& Schwarz Vector Network Analyzer (Model No. ZNB 20). The radiation characteristics are measured using a Keysight EXG analog signal generator (Model No. N5173B, $9 \mathrm{kHz}$ to $20 \mathrm{GHz}$ ), power meter and Agilent power sensor (Model No. E4412A, $100 \mathrm{pW}$ to $100 \mathrm{~mW},-70$ to $+20 \mathrm{dBm}, 10 \mathrm{MHz}$ to $18 \mathrm{GHz}$ ). The measured $S_{11}$ and radiation characteristics in the E-plane and H-plane are illustrated in Fig. 8 and Fig. 9.

The measured $S_{11}$ characteristic given in Fig. 8 show a minor shift in the desired mode $\left(\mathrm{HEM}_{11 \delta}\right)$ by $110 \mathrm{MHz}$. Also, the measured radiation characteristics of the proposed 3-LAAV loaded CDRA given in Fig. 9 show a deviation in boresight XPD for both the principal radiation planes from that obtained in simulation. Such deviation may be due to multiple errors introduced during fabrication and measurement process. An analysis on the possible errors introduced during fabrication is discussed in the below section.

\subsection{Analysis of Fabrication Errors}

Generally, in manual fabrication process an adhesive glue is used for mounting DRA on the metallic ground plane. The presence of non-zero glue layer, having lower permittivity $\left(\epsilon_{\mathrm{r}}=2.2\right)$ compared to the DRA $\left(\epsilon_{\mathrm{r}}=10.2\right)$, leads to discrepancies in the antenna radiation characteristics $[19,20]$.
A deviation in the radiation characteristics of CDRA due to the presence of adhesive layer of thickness $0.1 \mathrm{~mm}$ has been reported in literature [19]. Since the proposed 3-LAAV loaded CDRA design consists of 3-arrays of air vias at the bottom face of the DRA, creation of non-uniform adhesive layer with air gaps beneath the DRA covering the air vias is suspected. As already established in Section 4, boresight XPD of the proposed antenna is highly sensitive to minor variations in 3-LAAV parameters $\left(D_{\mathrm{AC}}, h_{\mathrm{AC}}, \Delta_{\mathrm{AC}}, \Delta_{\mathrm{LA}}\right)$. The presence of glue in this scenario primarily affects $D_{\mathrm{AC}}$ and $h_{\mathrm{AC}}$ of the proposed 3-LAAV. Thus, to accurately analyze the performance of the proposed 3-LAAV loaded CDRA, the design is re-analyzed with an additional adhesive layer of uniform thickness between the DRA and ground plane. The adhesive layer is designed having $\epsilon_{\mathrm{r}}=2.2, \tan \delta=0.022$ and thickness $0.1 \mathrm{~mm}$. The simulated performance characteristics of the 3-LAAV loaded CDRA with adhesive glue layer is given in Fig. 8 and Fig. 9. The presence of adhesive layer causes a minor shift in the resonant frequency but the boresight XP levels are impacted severely. A deterioration of $10 \mathrm{~dB}$ is observed in the BXPD levels at both the radiation planes. The additional deviation in BXPD levels may be due to the presence of uneven adhesive layer or air gaps at the bottom of the DRA which are unavoidable. The proposed 3-LAAV loaded CDRA provides an XP suppression of about $23 \mathrm{~dB}$ at the boresight, $21 \mathrm{~dB}$ and $5 \mathrm{~dB}$ over the $\pm 15 \% \mathrm{HPBW}$ in measurement at the E-plane and H-plane, respectively. The proposed 3-LAAV loaded CDRA offers a peak gain of $9 \mathrm{dBi}$ in measurement with peak radiation efficiency of $98 \%$. 


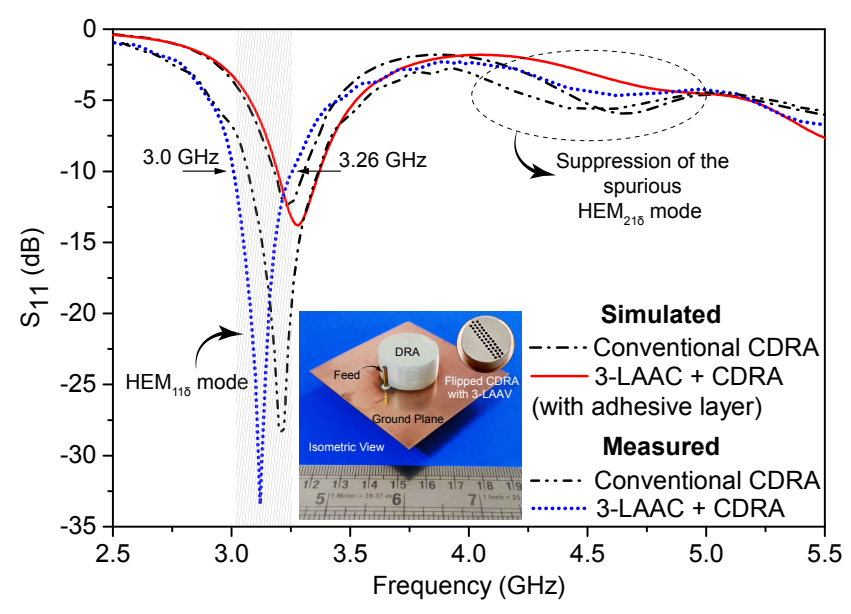

Fig. 8. Simulated and measured $S_{11}$ vs. frequency characteristics of 3-LAAV loaded CDRA with respect to conventional CDRA. Inset: Snapshot of the fabricated prototype.

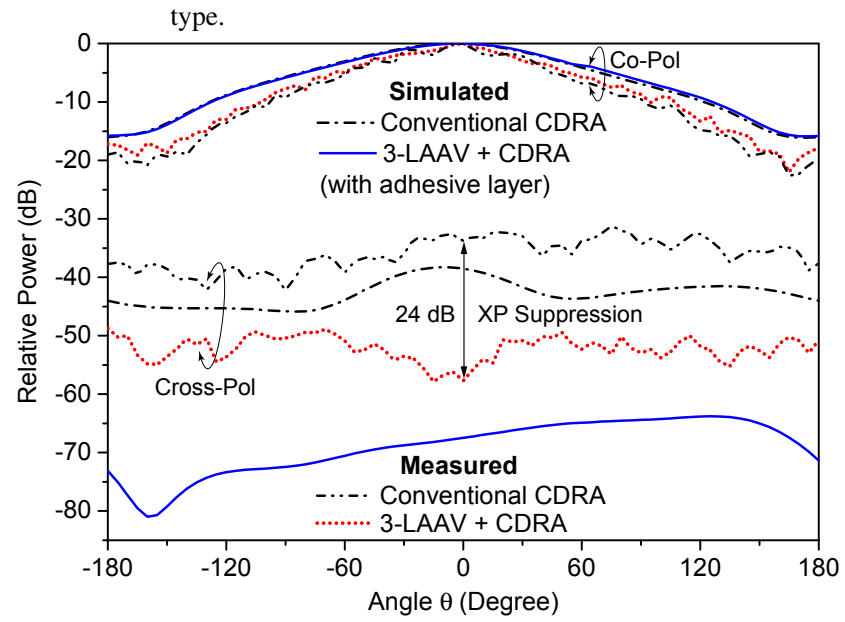

(a)

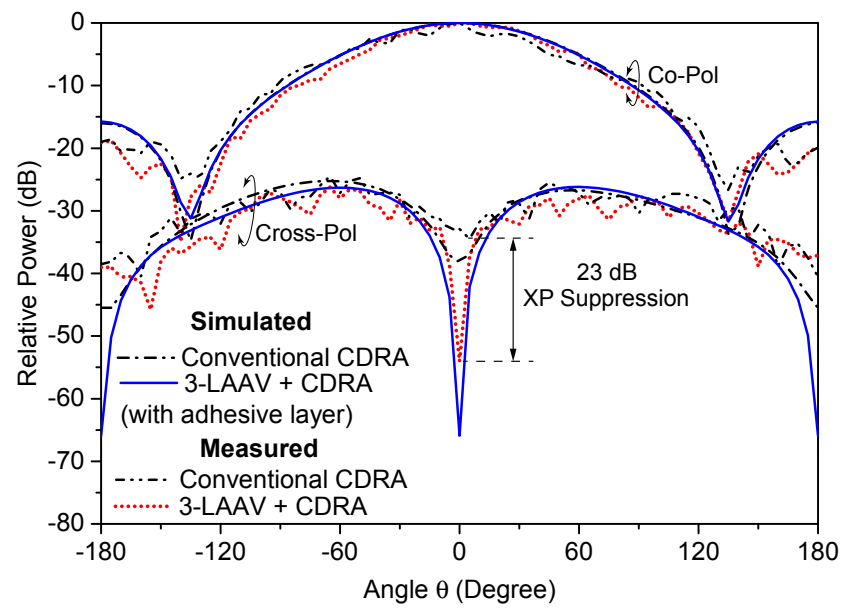

(b)

Fig. 9. Normalized radiation patterns in (a) E-plane and (b) $\mathrm{H}-$ plane of the proposed 3-LAAV loaded CDRA with respect to conventional CDRA.

\subsection{Performance Comparison}

The performance comparison of the proposed 3-LAAV loaded CDRA with some existing DRA designs on XP suppression and air vias/perforations is provided in Table 1 . The existing DRA designs with air vias/perforations [15-17] offer wide bandwidth with appreciable gain. But, compared to the proposed antenna design they suffer from poor XP performance and unstable broadside radiation pattern. Also, due to heavy machining involved in making the perforations in DRA the chances of deterioration of boresight XPD resulting from fabrication errors in these designs is very high. The existing DRA designs on XP suppression [13], [21] use metallic perturbation to suppresses the spurious mode by creating an inductive loading effect. However, these techniques suffer from increased ohmic loss which may affect the antenna radiation efficiency.

Compared to the existing antenna designs listed in Table 1, 3-LAAV loaded CDRA offers distinctively lower XP level by approximately $16 \mathrm{~dB}$ to $46 \mathrm{~dB}$ at the boresight, $5 \mathrm{~dB}$ to $45 \mathrm{~dB}$ over the $\pm 15 \%$ HPBW in E-plane and $3 \mathrm{~dB}$ to $28 \mathrm{~dB}$ over the $\pm 15 \%$ HPBW in H-plane. It also offers a boresight XPD error tolerance of about $26 \mathrm{~dB}$ which is about $16 \mathrm{~dB}$ to $22 \mathrm{~dB}$ higher than other existing antenna designs. But, its bandwidth is comparatively lower than the other enlisted DRA designs. Efforts to improve the bandwidth of the proposed 3-LAAV loaded CDRA may be made in future. However, the considerably low XP levels along with high gain and stable broadside radiation pattern offered by the proposed 3-LAAV loaded CDRA design makes it suitable for satellite earth station and fixed radio antenna applications over all other existing prototypes.

\section{Conclusion}

In this paper, a high cross-polarization discrimination offering CDRA loaded with three linear arrays of air vias (3-LAAV) has been studied and validated experimentally. Strategic XP field perturbation by effective permittivity modification in the dielectric material creating a capacitive loading effect has been found as the key design aspect for controlling the spurious $\mathrm{HEM}_{21 \delta}$ mode. Also, the sensitivity of the boresight XPD on the 3-LAAV design parameters established from the parametric analysis acts as a fabrication guideline indicating that utmost care has to be taken during machining process of the proposed CDRA.

Although high boresight XPD of around $38 \mathrm{~dB}$ is achievable while designing the standalone CDRA element but the integration of the antenna in a system may inevitably deteriorate the XP performance due to losses incurred from unwanted reflection/radiation, component integration, and coupling. As a prospective solution to such issues, the proposed 3-LAAV structure essentially provides an extra tolerance by offering a high XPD of about $56 \mathrm{~dB}$ at the antenna boresight, $55 \mathrm{~dB}$ over $\pm 15 \%$ of HPBW (E-plane) and $38 \mathrm{~dB}$ over $\pm 15 \%$ of HPBW (H-plane) in measurement, respectively. 


\begin{tabular}{|c|c|c|c|c|c|c|c|c|}
\hline $\begin{array}{l}\text { Compared } \\
\text { antenna } \\
\text { design }\end{array}$ & $\begin{array}{c}\text { XP } \\
\text { suppression } \\
\text { technique }\end{array}$ & $\begin{array}{c}\text { Boresight } \\
\text { XPD (both } \\
\text { the principal } \\
\text { radiation } \\
\text { planes) }\end{array}$ & $\begin{array}{l}\text { XPD over } \\
\pm 15 \% \text { of } \\
\text { HPBW } \\
\text { (E- } \\
\text { plane) })^{\dagger}\end{array}$ & $\begin{array}{c}\text { XPD over } \\
\pm 15 \% \text { of } \\
\text { HPBW } \\
(\text { H- } \\
\text { plane })^{\dagger} \\
\end{array}$ & Gain & Bandwidth & $\begin{array}{l}\text { Broadside } \\
\text { Radia- } \\
\text { tion } \\
\text { Pattern }\end{array}$ & $\begin{array}{c}\text { Boresight XPD } \\
\text { Error } \\
\text { Tolerance (Ref. } \\
\text { Value }=\mathbf{3 0} \mathbf{d B}^{\dagger} \\
\end{array}$ \\
\hline [12] & $\begin{array}{l}\text { Differential } \\
\text { Feed }\end{array}$ & $34 \mathrm{~dB}$ & - & - & $6.7 \mathrm{dBi}$ & $\begin{array}{l}4100 \\
\mathrm{MHz}\end{array}$ & Symmetric & $4 \mathrm{~dB}$ \\
\hline [13] & Metal Post & $40 \mathrm{~dB}$ & $36 \mathrm{~dB}$ & $31 \mathrm{~dB}$ & $6.01 \mathrm{dBi}$ & $100 \mathrm{MHz}$ & Symmetric & $10 \mathrm{~dB}$ \\
\hline [13] & $\begin{array}{c}\text { Rectangular } \\
\text { Metal Bar }\end{array}$ & $36 \mathrm{~dB}$ & $31 \mathrm{~dB}$ & $34 \mathrm{~dB}$ & $6.01 \mathrm{dBi}$ & i $520 \mathrm{MHz}$ & Symmetric & $6 \mathrm{~dB}$ \\
\hline [14] & $\begin{array}{c}\text { Dielectric } \\
\text { Perturbation }\end{array}$ & - & $50 \mathrm{~dB}$ & $35 \mathrm{~dB}$ & $6.54 \mathrm{dBi}$ & i $350 \mathrm{MHz}$ & Symmetric & - \\
\hline [15] & $\begin{array}{l}\text { Perforated } \\
\text { Stacked } \\
\text { Multi- } \\
\text { Permittivity } \\
\text { DRA }\end{array}$ & $30 \mathrm{~dB}$ & $30 \mathrm{~dB}$ & $20 \mathrm{~dB}$ & $\begin{array}{c}1.5- \\
6.2 \mathrm{dBi}\end{array}$ & $\begin{array}{l}14900 \\
\mathrm{MHz}\end{array}$ & $\begin{array}{l}\text { Minor } \\
\text { Tilting }\end{array}$ & $0 \mathrm{~dB}$ \\
\hline$[16]$ & $\begin{array}{c}\text { Array of } \\
\text { Square Slots } \\
\& \text { Edge } \\
\text { Grounding }\end{array}$ & $10 \mathrm{~dB}$ & $10 \mathrm{~dB}$ & $10 \mathrm{~dB}$ & $7 \mathrm{dBi}$ & $\begin{array}{l}1700 \\
\mathrm{MHz}\end{array}$ & Tilted & $-20 \mathrm{~dB}$ \\
\hline [17] & $\begin{array}{l}\text { T-shaped } \\
\text { Perforated } \\
\text { DRA }\end{array}$ & $20 \mathrm{~dB}$ & $40 \mathrm{~dB}$ & $20 \mathrm{~dB}$ & $\begin{array}{c}5- \\
6 \mathrm{dBi}\end{array}$ & $\begin{array}{l}1400 \\
\mathrm{MHz}\end{array}$ & Tilted & $-10 \mathrm{~dB}$ \\
\hline [21] & $\begin{array}{l}\text { Feed with } \\
\text { Parallel } \\
\text { Standing } \\
\text { Strips }\end{array}$ & $30 \mathrm{~dB}$ & $29 \mathrm{~dB}$ & $25 \mathrm{~dB}$ & $\begin{array}{l}5.5- \\
7 \mathrm{dBi}\end{array}$ & $\begin{array}{l}1400 \\
\mathrm{MHz}\end{array}$ & Asymmetric & $0 \mathrm{~dB}$ \\
\hline $\begin{array}{c}\text { Proposed } \\
\text { 3-LAAV } \\
\text { Loaded } \\
\text { CDRA } \\
\text { (Fabricated } \\
\text { \& Measured) }\end{array}$ & $\begin{array}{l}\text { Linear } \\
\text { arrays of } \\
\text { air vias }\end{array}$ & $56 \mathrm{~dB}$ & $55 \mathrm{~dB}$ & $38 \mathrm{~dB}$ & $9 \mathrm{dBi}$ & $260 \mathrm{MHz}$ & Symmetric & $26 \mathrm{~dB}$ \\
\hline
\end{tabular}

\footnotetext{
${ }^{\dagger}$ As per the standard polarization requirements for point-to-point communication systems [7], [8].

Tab. 1. Performance comparison of the analysed antenna designs with other antenna designs on XP suppression and air vias/perforations existing in literature
}

\section{Acknowledgments}

This work is partially supported by the Council of Scientific and Industrial Research, India, under Grant 09/106(0182)/2019-EMR-I.

\section{References}

[1] LUDWIG, A. The definition of cross polarization. IEEE Transactions on Antennas and Propagation, 1973, vol. 21, no. 1, p. 116-119. DOI: 10.1109/TAP.1973.1140406

[2] VOLAKIS, J. L. Radiometer Antennas in Antenna Engineering Handbook. $4^{\text {th }}$ ed., New York (USA): McGraw-Hill Education, 2007. ISBN 978-0-07-147574-7

[3] PUJARA, D., SHARMA, S. B., CHAKRABARTY, S. B. Historical and planned uses of antenna technology for space-borne microwave radiometers. IEEE Antennas and Propagation Magazine, 2011, vol. 53, no. 3, p. 95-114. DOI: 10.1109/MAP.2011.6028425

[4] BECKMAN, C., WAHLBERG, U. Antenna systems for polarization diversity. Microwave Journal, 1997, vol. 40, p. 330-334. ISSN 0192-6225

[5] GHOBRIAL, S. I. Cross-polarization in satellite and earth-station antennas. Proceedings of the IEEE, March 1977, vol. 65, no. 3, p. 378-387. DOI: 10.1109/PROC.1977.10490

[6] KISHK, A. A. Dielectric resonator antenna, a candidate for radar applications. In Proceedings of the 2003 IEEE Radar Conference (Cat. No. 03CH37474), Huntsville (USA), 2003, p. 258-264. DOI: $10.1109 /$ NRC.2003.1203411

[7] Earth Station Performance Requirements, SES, Rooseveltplantsoen 4, The Hague 2517 KR, Netherlands, 2006 [Online] Cited 2019-07-05. Available at: https://www.ses.com/sites/default/files/201703/es_performance_requirements_0.pdf 
[8] Fixed Radio Systems; Characteristics and requirements for point-to-point equipment and antennas. Part 4: Antennas, European Telecommunications Standards Institute (ETSI), 650 Route des Lucioles, F-06921 Sophia Antipolis Cedex, France, 2017 [Online] Cited 2019-07-06. Available at: https://www.etsi.org/deliver/etsi_en/302200_302299/30221704/02.0 1.01_60/en_30221704v020101p.pdf

[9] SKOLNIK, M. I. Radar Handbook. New York (USA): McGraw-Hill Professional, 2008. ISBN 978-0071485470

[10] KAJFEZ, D., GLISSION, A. W., JAMES, J. Computed modal field distributions for isolated dielectric resonators. IEEE Transactions on Microwave Theory and Techniques, 1984, vol.32, no. 12, p. 1609-1616. DOI: 10.1109/TMTT.1984.1132900

[11] AL-ZOUBI, A. S., KISHK, A. A., GLISSON, A. W. A linear rectangular dielectric resonator antenna array fed by dielectric image guide with low cross polarization. IEEE Transactions on Antennas and Propagation, 2010, vol. 58, no. 3, p. 697-704. DOI: 10.1109/TAP.2009.2039294

[12] SINGH, A., SHARMA, S. K. Investigations on wideband cylindrical dielectric resonator antenna with directive radiation patterns and low cross polarization. IEEE Transactions on Antennas and Propagation, 2010, vol. 58, no. 5, p. 1779-1783. DOI: 10.1109/TAP.2010.2044330

[13] GUHA, D., GAJERA, H., KUMAR, C. Cross-polarized radiation in a cylindrical dielectric resonator antenna: identification of source, experimental proof, and its suppression. IEEE Transactions on Antennas and Propagation, 2015, vol. 63, no. 4, p. 1863-1867. DOI: 10.1109/TAP.2015.2398127

[14] GAJERA, H., GUHA, D., KUMAR, C. New technique of dielectric perturbation in dielectric resonator antenna to control the higher mode leading to reduced cross-polar radiations. IEEE Antennas and Wireless Propagation Letters, 2017, vol. 16, p. 445-448. DOI: 10.1109/LAWP.2016.2582516

[15] ZUBIR, I. A., Othman, M., Ubaid, U., et al. A low-profile hybrid multi-permittivity dielectric resonator antenna with perforated structure for $\mathrm{ku}$ and $\mathrm{k}$ band applications. IEEE Access, 2020, vol. 8, p. 151219-151228. DOI: 10.1109/ACCESS.2020.3016432

[16] PATEL, P., MUKHERJEE, J., MUKHERJEE, B. Compact wideband perforated rectangular dielectric resonator antenna. 2015 IEEE International Symposium on Antennas and Propagation \& USNC/URSI National Radio Science Meeting, 2015, p. 41-42. DOI: 10.1109/APS.2015.7304406

[17] PATEL, P., ERRAMShETTY, M. New wideband t-shaped perforated dielectric resonator antenna. 2017 Mediterranean Microwave Symposium (MMS), Marseille, 2017, p. 1-3. DOI: $10.1109 / M M S .2017 .8497150$

[18] MULDAVIN, J. B., REBEIZ, G. M. Millimeter-wave tapered-slot antennas on synthesized low permittivity substrates. IEEE Transactions on Antennas and Propagation, 1999, vol. 47, no. 8, p. 1276-1280. DOI: $10.1109 / 8.791943$
[19] FAIZ, A.M., GOGOSH, N., KHAN, S.A., et al. Effects of an ordinary adhesive material on radiation characteristics of a dielectric resonator antenna. Microwave and Optical Technology Letters, 2014, vol. 56, no. 6, p. 1502-1506. DOI: 10.1002/mop.28349

[20] JUNKER, G.P., KISHK, A.A., GLISSON, A.W., et al. Effect of fabrication imperfections for ground-plane-backed dielectric resonator antennas. IEEE Antennas and Propagation Magazine, 1995, vol. 37, p. 40-47. DOI: $10.1109 / 74.370580$

[21] RASHIDIAN, A., SHAFAI, L., KLYMYSHYN, D. M. Compact wideband multimode dielectric resonator antennas fed with parallel standing strips. IEEE Transactions on Antennas and Propagation, 2012, vol. 60, no. 11, p. 5021-5031. DOI: 10.1109/TAP.2012.2210018

\section{About the Authors...}

P Soni REDDY received the B.Tech. degree in ECE from Academy of Technology, West Bengal, India, in 2011 under the affiliation of former WBUT and the M.Tech. degree in ECE from Kalyani Govt. Engineering College, Kalyani, West Bengal, India, in 2016 under the affiliation of MAKAUT, West Bengal. Since April 2019, she has been working as a CSIR Senior Research Fellow (under Grant 09/106(0182)/2019-EMR-I) in the Department of Engineering \& Technological Studies, University of Kalyani, West Bengal, India. Her research areas include enhancement of radiation characteristics of microstrip patch and dielectric resonator antennas, and compact multiband DGS integrated microstrip antenna.

Rahul MONDAL received the B.Tech. degree in Electronics \& Instrumentation Engineering from Department of Engineering \& Technological Studies, University of Kalyani, Kayani, West Bengal, India, in 2015 and the M.Tech. degree in Communication Engineering in 2017. He is currently pursuing Ph.D. (Tech.) degree at D.E.T.S, University of Kalyani. His research areas include Frequency Selective Surfaces, Microstrip Antenna, and Rasorber.

Partha Pratim SARKAR was felicitated with a Ph.D in Engineering from Jadavpur University in the year 2002. He has obtained his M.E from Jadavpur University in the year 1994. He was in the rank of Reader during the period January 1997 to January 2005 . He is presently working in the rank of Professor since January 2005 at the Dept. of Engineering \& Technological Studies, University of Kalyani. His area of research includes Microstrip Antenna, Microstrip Filter, Frequency Selective Surfaces and Artificial Neural Network. 